PISA intervention to change resident attitudes. Given the paucity of studies on suicide prevention training, these data provide a starting point for developing and evaluating an interdisciplinary training model in suicide assessment and intervention. More rigorous studies examining the effects of the PISA intervention on suicidology knowledge and skills and the impact on clinical practice are needed to further clarify this intervention's educational impact.

We thank Drs. Paul Links and Bruce Ballon for their valuable feedback and thoughtful comments on previous drafts of this manuscript. This paper was presented at the Canadian Group Psychotherapy Association 28th Annual Meeting in Toronto, Ontario, on November 8, 2007.

At the time of submission, the authors reported no competing interests.

\section{References}

1. Kleespies PM, Penk WE, Forsyth JP: The stress of patient suicidal behavior during clinical training: incidence, impact, and recovery. Prof Psychol Res Pract 1993; 24:293-303
2. Ruskin R, Sakinofsky I, Bagby RM, et al: Impact of patient suicide on psychiatrists and psychiatric trainees. Acad Psychiatry $2004 ; 28: 104-110$

3. Ellis TE, Dickey TO, Jones EC: Patient suicide in psychiatry residency programs. Acad Psychiatry 1998; 22:181-189

4. Balon R: Encountering patient suicide: the need for guidelines. Acad Psychiatry 2007; 31:336-337

5. Fang F, Kemp J, Jawandha A, et al: Encountering patient suicide: a resident's experience. Acad Psychiatry 2007; 31 : 340-344

6. Billings JH, Rosen DH, Asimos C, et al: Observations on long-term group therapy with suicidal and depressed persons. Life-Threatening Behavior 1974; 4:160-170

7. Motto JA: Starting a therapy group in a suicide prevention and crisis center. Suicide Life Threat Behav 1979; 9:47-56

8. Bergmans Y, Links P: A description of a psychosocial/psychoeducational intervention for persons with recurrent suicide attempts. Crisis 2002; 23:156-160

9. Kruger J, Dunning D: Unskilled and unaware of it: how difficulties in recognizing one's own incompetence lead to inflated self-assessments. J Pers Soc Psychol 1999; 77:11211134

\title{
Facing Our Frustration
}

A black car is chasing me. When I leave the clinic, it will be outside, waiting for me to surrender. The government must be up to this, playing tricks on me, as if I'm some human experiment. I don't know why I came today for my appointment. No one can stop this. Not even you.

Scott Krakower, D.O. Department of Psychiatry, Zucker Hillside Hospital, Long Island Jewish Medical Center, Glen Oaks, New York 